\title{
Genetic Epidemiology of Schizophrenia and Bipolar Disorder: a review
}

\author{
A. Anuradha ${ }^{1}$, V. Lakshmi Kalpana ${ }^{2}$ \\ ${ }^{1}$ DST Women Scientist, \\ ${ }^{2} \mathrm{Head}$ \\ Department of Human Genetics, Andhra University, Visakhapatnam - 530003 \\ Corresponding author: Dr. A. Anuradha \\ Email-dranuhg@gmail.com
}

\begin{abstract}
There is considerable significance for partial genetical overlap between schizophrenia and bipolar disorders based on family and twin studies. Though the two disorders are treated differently by their diagnostic categories, recent evidence supports that they are more closely associated. Inspite of considerable overlap in epidemiologic features, there is no specification of the risk factors. Moreover, a significant overlap in the genes contributing to schizophrenia and bipolar disorder has been revealed by family and twin studies. Keeping all these in view, the findings in various studies from the worldwide are reviewed after a careful research of articles published in Indian journal of psychiatry, Libigenesis, Scihub and Pubmed.
\end{abstract}

Keywords: Epidemiology, Schizophrenia, Bipolar mood disorder, Genetic overlap, Family and Twin studies.

(Paper received $-16^{\text {th }}$ July 2018, Peer review completed $-30^{\text {th }}$ August 2018)

(Accepted $-9^{\text {th }}$ September 2018)

\section{INTRODUCTION}

Psychiatric epidemiology deals with the difficulties encountered in conceptualising and measuring mental disorders. [1] and comprises distribution, frequency, causes of disorder, diagnosis and methods employed to control the occurrence of illness. [2]

A clinically significant manifestation of behavioural, psychological or biological dysfunction that occurs in an individual with stress is considered as mental disorder according to DSM-5 [3] and ranging from subclinical states to very severe forms. Mental health problems are easy to recognize, define, diagnose and treat, can be called as 'Visible Mental Health Problems' which are further classified into Major and Minor mental disorders. In contrast, 'Invisible Mental Health Problems' are difficult to recognize, define and diagnose. Because of the difficulty in defining and identifying the cases, Psychiatric epidemiological studies have ignored this category.

Schizophrenia is a chronic and severe mental disorder with a prevalence of $1 \%$ (roughly equal in males and females [4]. Although schizophrenia is not as common as other mental disorders, the symptoms can be very disabling. The common symptoms are delusions and hallucinations disorganisation, dysfunction and altered cognitive functioning.

Bipolar disorder associated with extreme mood swings from depression to mania, and also known as manic depressive disorder and shows equal prevalence in both males and females with $1 \%$ [5]. The 
symptoms are disturbances in mood ranging from extreme elation (mania) to severe depression often accompanied by psychotic features and cognitive changes.

There is substantial evidence from family and twin studies, a partial overlap exists in the familial susceptibility to schizophrenia and bipolar disorder. Twin studies provide further evidence for a genetic etiology for this common familial predisposition. With this knowledge, the present study attempted to review the genetic epidemiology of schizophrenia and bipolar disorder.

\section{GENETIC EPIDEMIOLOGY}

The epidemiology of Schizophrenia and bipolar disorder show significant similarities such as prevalence of approximately 1\% [6-7] gender distribution and the age of onset before 25 years [7-8]. The two disorders are associated with high morbidity and health services use, and both convey an increased risk of self-harm and suicidal behavior [9]. An overlap observed not only in phenomenology and epidemiology of Schizophrenia and bipolar disorder but also in risk factors. Due to scarcity of literature, it should not be confirmed that any risk factor is specific to any diagnostic category. [10]

Basing on overlap in phenomenology, epidemiology, and risk factors of schizophrenia and bipolar disorder, a proposal of dimensional model was put forth by Van Os and Murray [11] which reveals a spectrum of psychotic disorders, under the influence of two major types of risk factors. The first is a neurodevelopmental factor that operates on any form of psychosis, with early onset and poor outcome. Those patients at the more "neurodevelopmental end of the spectrum" tend to have a stronger family history of schizophrenia are more likely to be male.

The second is a social reactive factor reflecting a genetic predisposition to develop psychotic symptoms when exposed to stress and adverse events. This effect is maximal at the acute-onset and good-outcome end of the psychosis spectrum. Patients at this "social-reactive end of the spectrum" typically have affective symptoms or a relative with affective disorder and are more likely to be women. If schizophrenia and bipolar disorder have similar epidemiology and genetic risk factors, then it would be expected to find common familial aggregation for the two conditions.

\section{Schizophrenia}

More literature is available regarding the genetic basis of schizophrenia than any other psychiatric disorder since last century. An average relative risk of 8.9 to first-degree relatives was observed irrespective of wide differences in methods, samples, and geographic locations, controlled family studies.

In addition to this, due to role of genetic factors in the familial aggregation, four-fold greater concordance rate of schizophrenia is observed in monozygotic compared to dizygotic twins from 12 studies till date. The average heritability in liability to schizophrenia across 12 studies is 0.81 . [12] Some studies show that multifactorial etiology also plays important role in the genetic epidemiology of schizophrenia [12-14]. According to Tienari and others [15], study, the role of environmental factors (i.e., multiple factors that may affect brain development) to schizophrenia's etiology showed that adoptive family environment was associated with schizophrenia spectrum disorders among genetically vulnerable individuals.

The advances in the research reveals environmental risk factors underlying schizophrenia and other neurodevelopmental disorders. A focus on early developmental factors in the etiology of schizophrenia was due to an increased incidence of numerous neurodevelopmental abnormalities among children at high risk for the development of schizophrenia based on having an affected parent compared to offspring of parents without schizophrenia [15].

Obstetric complications [16], prenatal factors such as nutritional deficiencies [17], increased paternal age [18], minor physical anomalies and neurologic soft signs [19], maternal infections [20], and cannabis use [21-22] are considered to be some of the other specific environmental risk factors which are currently under investigation. Apart from these, other environmental exposures are socioeconomic inequalities [23], teenage motherhood [24] and urban environments [25-26] have broad impact on mental health of exposed youth.

Another important potential environmental risk factor is the increased risk for the development of schizophrenia among immigrants in several different countries, including East African immigrants to 
Sweden [27], Surinamese immigrants to the Netherlands [28], Afro-Caribbean immigrants to the United Kingdom [29], Finnish immigrants to Sweden [30], and European immigrants to Canada [31]. Although selective migration may be one explanation, there is converging evidence that socially disrupted environments may trigger the onset of schizophrenia in susceptible individuals.

\section{Bipolar Disorders}

Bipolar disorder (manic depression) and major depression are subtypes of mood disorders. From genetical point of view, bipolar disorder is one of the most extensively studied psychiatric disorders [32]. Bipolar disorder has been shown to have markedly greater familial aggregation and heritability than of major depression. Controlled family studies show a 2- to 3-fold risk of major depression among relatives of probands with major depression, and greater than a 10 -fold risk to first-degree relatives of bipolar patients. As per the Swedish and Danish population-based treatment registries, there was a 7-fold increased risk and a 6.5 increased risk of bipolar disorder among first-degree relatives of probands with bipolar disorder in the Swedish [33] and Danish [34] registries. Other family studies of the mood disorder spectrum have also demonstrated specificity of the core components of psychosis, mania, and major depression [35,36]. All these studies confirm the significantly greater heritability of mania than depression reported by McGuffin et al.,2003 in the Maudsley Twin Registry [37].

The research advances in identifying early manifestations of bipolar disorder by comparing early manifestations of mood disorders among offspring of parents with bipolar disorder compared to those of controls [38-41]. These studies have also explained developmental patterns of expression of comorbidity with other disorders such as Attention-Deficit/Hyperactivity Disorder (ADHD) [41]. Twin studies by Merikangas and $\mathrm{Yu}$ [42] reported that the concordance rate for monozygotic twins is over five times that of dizygotic twins in bipolar disorder, whereas it is less striking but notable differences for depression. It is therefore bipolar exhibits significantly greater heritability estimates than those with major depression. For example, the best fitting model of the heritability of bipolar disorder in a Finnish twin study was 0.93 [43]. McGuffin et al.,2003 [37] also estimated the heritability of mania and depression, the core components of bipolar disorder, in the Maudsley Twin Study. They observed that the heritability of mania was markedly greater and distinguishable from that of major depression.

\section{Evidence from family studies}

It was revealed by family studies that the first-degree relatives of probands with schizophrenia are at increased risk for schizophrenia, schizoaffective disorder, schizotypal personality disorder, unipolar depression and bipolar disorder [44-45]. The risk of bipolar disorder in first-degree relatives was $2.4 \%$ if the proband was schizophrenic compared with the $0.3 \%$ risk for the relatives of control individuals [46].

The diagnostic reviews of three independent genetic studies on schizophrenia including the Danish Adoption Study [47], the Iowa 500 Family Study [48], and the Roscommon Family Study [49] was done by Kendler and Gardner [48]. The odds ratio of unipolar depression and bipolar disorder in first-degree relatives of schizophrenic probands were 1.3 and 1.9 respectively (statistical significance was not found in the latter). Thus, the aggregated outcome of the three studies provide support for a modest familial coaggregation of schizophrenia and affective illness.

The family studies of bipolar disorder show that first-degree relatives of bipolar probands have an increased risk to develop bipolar disorder, schizoaffective disorder, unipolar depression, and also schizophrenia [44, 49-50]. The first-degree relatives had an increased risk of schizophrenia, ranging from $2.5 \%$ if they were siblings to $4.8 \%$ if they were offspring of their bipolar probands [51]. Another study by Scharfetter and Nusperli [52] states that the risk of schizophrenia in first-degree relatives was $8.9 \%$ and $3.3 \%$ if the proband had schizophrenia and bipolar disorder, respectively. The risks of schizophrenia in relatives were $3.2 \%$ if the proband was manic, and $0.6 \%$ if the proband was normal [53] in Iowa 500 Family Study.

Some studies may not show increased rates of schizophrenia or bipolar disorder among the first-degree relatives of bipolar disorder or schizophrenia probands, respectively [54-55]. The reason might be attributed to insufficient power to detect increases in risk that are of small to moderate effect. From overall information, it can be concluded that a partial overlap exists in the familial susceptibility to schizophrenia 
and bipolar disorder. Further evidence for a genetic etiology for this common familial predisposition is available from twin studies.

\section{Evidence from Twin Studies}

The siblings of index twins with schizophrenia showed a similar prevalence of affective disorder and schizophrenia, although their parents were more likely to suffer affective disorder than schizophrenia [56]. Further research from twin sets support the notion of some shared liability among subgroups of patients with schizophrenia and affective illness [57].

Cardno and others [58] analysed 224 proband wise-ascertained twin pairs from the Maudsley Twin Psychosis Series. From Research Diagnostic Criteria [RDC] and DSM-III-R and ICD-10 definitions, heritability estimates for schizophrenia were between $82 \%$ and $85 \%$ in schizoaffective disorder and mania. Hence the heritability of schizophrenia, schizoaffective disorder, and mania is markedly, and significantly and prominently similar. By using model fitting techniques, Cardno and others [59] analysed 177 twin pairs from the same Maudsley twins sample. They present both common and diagnostic-specific genetic contributions to variance in liability to schizophrenia and mania; though, diagnostic-specific genetic effects for schizoaffective disorder are negligible. Thus, the conclusion from above study states a significant overlap in the genes contributing to RDC-defined schizophrenia, schizoaffective disorder, and mania.

Typically, clinically confirmed family studies during the 20th century, employing main-lifetime diagnoses, generally did not find a significant excess of bipolar disorder among the relatives of individuals with schizophrenia, or vice versa, [50, 60-61] supporting the concept of an etiological dichotomy between the two disorders. However, these studies include a degree of familial coaggregation due to sample size limitations [62]. Based on the Maudsley twin register in London13 found no co-occurrence of schizophrenia and bipolar disorder in MZ twin pairs when a hierarchical main-lifetime diagnosis was employed, again with the caveat of sample size limitations. Nevertheless, when a non-hierarchical lifetimeever approach was taken, significant coaggregation was observed between schizophrenic and manic episodes in twin pairs, and model-fitting exhibit a significant genetic correlation of 0.68 between lifetimeever schizophrenia and mania.

Through examination of the underlying components of mental disorders and their biologic correlates, work has begun to go beyond categorical phenotypes. In addition to this, a cohort design of twin studies gives valuable information on the order of exposure and disease onset, as well as the temporal presentation of symptoms and syndromes that can inform current evidence regarding common genetic and environmental risk factors across psychiatric disorders. The role of genetic and environmental factors in the aetiology of psychiatric disorders will be better understood by increasing collaboration of the same.

\section{RISK FACTORS OF SCHIZOPHRENIA AND BIPOLAR DISORDER}

Besides well-established genetic risk factors, multiple environmental factors are also clarified ranging from prenatal development to obstetric complications. One of the genetical risk factor is increased paternal age [63], and other preconceptual risk factors are long gap between pregnancies and reduced maternal folate levels. Environmental factors include residing in urban areas, stressful lifestyle, increased pollution and more of high risk behaviours are considered to increase the risk to develop schizophrenia.

Though research proved that genetics play an important role, the basic cause of bipolar disorder is still unclear. In two thirds of bipolar disorder individuals, definitely have both affected mother and father. But certain chemicals such as serotonin, dopamine and nor adrenaline were isolated in the brain responsible for chemical imbalance, in turn leading to mood swings. These mood swings are considered to be the main symptom associated with bipolar disorder. Hormonal imbalances and environmental factors like abuse, mental stress, a "significant loss," or some other traumatic event which may contribute to or trigger bipolar disorder.

\section{Symptoms of Schizophrenia and Bipolar Disorder}

Schizophrenia patients have delusions or unusual thoughts, or feel extremely suspicious and be away from reality. They also have audio or visual hallucinations which are negative or frightening. Disorganised 
speech or behaviour, decreased participation in daily activities, difficulty with concentration and memory may also be present. They feel that other people are plotting against them.

Bipolar disorder symptoms are mainly related to behaviour. The manic phases are recognized by distraction, inability to concentrate, rapid speech, restlessness and participation in risky activities whereas depressive phases can be manifested by lack of interest in hobbies or other previously enjoyed activities, fatigue, difficulty with concentration, memory, disturbances in sleep or eating habits and suicidal thoughts.

\section{Cognitive Impairment of Schizophrenia and Bipolar Disorder}

The primary concern in schizophrenia is cognitive impairments which is probably due to biological dysfunction, but research is unsatisfactory to prove the genetic association between the two. Phonomics strategies focus concomitant study of multiple phenotypes across biological scales assist, especially if the high heritabilities of schizophrenia and cognitive impairments are due to more numbers of genetic variants with less effect.

Since Emil Kraepelin described the syndrome of dementia praecox in 1893 [64], cognitive impairment has been seen as a hallmark of schizophrenia because cognitive functions might prove more tractable targets for genetic study than are the characteristic symptoms used to diagnose schizophrenia.

It is studied that both schizophrenia and cognitive impairment are highly heritable and may have genetically mediated neurodevelopmental anomaly as both are susceptible and invariably accompanies the syndrome. Regardless of whether the estimate is derived from healthy or ill groups [65-66], the heritability of schizophrenia is estimated to be greater than heritability of cognitive phenotypes.

From advanced research, it is evident that bipolar affective disorders have cognitive impairments. The cognitive impairments are more pronounced in other psychiatric (eg, schizophrenia) or neurological (eg, Alzheimer dementia) disorders than bipolar disorder. However, the cognitive impairments are relatively less, reduced neuropsychological ability appears to significantly affect psychosocial functioning in patients with bipolar disorder.

Nevertheless, neuropsychological functioning is not a unitary but multiple process, which includes partly separable cognitive domains like attention, processing speed, working or declarative memory, executive processing, language, intelligence quotient [IQ]. Recently, there is scanty evidence about IQ deficits in patients with bipolar disorder. Attentional, executive, and declarative or long-term memory impairments were observed in patients with bipolar disorder having cognitive difficulties.

\section{Diagnosis of Schizophrenia and Bipolar Disorder}

The way in which schizophrenia, bipolar disorder, and schizoaffective disorder are defined can have a significant effect on different ways of genetic relationships between them. The most common approach in psychiatric genetics research is to assign a single main-lifetime diagnosis to each individual using the relevant version of the Diagnostic and Statistical Manual of Mental Disorders (DSM)6 or another operational diagnostic classification system, based on the predominant clinical picture during a person's lifetime.

\section{Schizophrenia}

Physical examination: This may be done to rule out other problems that could be causing symptoms and to check for any related complications.

Tests and screenings: These may include tests that help to rule out any other conditions with similar symptoms, and screening for alcohol and drugs. The tests required are Imaging studies like MRI or CT scan.

Psychiatric evaluation: A doctor or mental health professional checks mental status by observing appearance and demeanour and asking about thoughts, moods, delusions, hallucinations, substance use, and potential for violence or suicide. This also includes a discussion of family and personal history.

Diagnostic criteria for schizophrenia: A doctor or mental health professional may use the criteria in the Diagnostic and Statistical Manual of Mental Disorders (DSM-5), published by the American Psychiatric Association. 


\section{Bipolar Disorder}

A diagnostic exam for bipolar disorder generally consists of the following:

Psychological evaluation: The doctor or bipolar disorder specialist will conduct a complete psychiatric history. The patients will answer questions about their symptoms, the history of the problem, any treatment previously received, and family history of mood disorders.

Medical history and physical: No specific lab tests are available for identifying bipolar disorder, but the doctor should conduct a medical history and physical exam in order to rule out illnesses or medications that might be causing symptoms. Screening for thyroid disorders is particularly important, as thyroid problems can cause mood swings that imitate bipolar disorder.

\section{TREATMENT OF SCHIZOPHRENIA AND BIPOLAR DISORDER}

\section{Schizophrenia}

Schizophrenia requires lifelong treatment, even when symptoms have subsided. Treatment with medications and psychosocial therapy can help manage the condition. In some cases, hospitalization may be needed.

A psychiatrist experienced in treating schizophrenia usually guides treatment. The treatment team also may include a psychologist, social worker, psychiatric nurse and possibly a case manager to coordinate care. The full team approach may be available in clinics with expertise in schizophrenia treatment.

People with schizophrenia tended to take only small amounts of exercise. The reason for this has not been demonstrated, but factors such as features of the illness, sedative medication and lack of opportunity and general motivation may be relevant.

\section{Bipolar Disorder}

Bipolar disorder is a lifelong condition. It runs an unpredictable course of ups and downs. When left untreated, these ups and downs can be devastating. The recurring manic and depressive episodes that characterize the disease make it difficult to lead a stable, productive life. In the manic phase, the patient may be hyperactive and irresponsible. In the depressive phase, it may be difficult to do anything at all. Early diagnosis and treatment can help to avoid these problems.

Successful treatment of Bipolar disorder depends on a combination of factors. Medication alone is not enough in order to get the most out of treatment, it's important to educate the patient about the illness, communicate with doctors and therapists, have a strong support system and by making healthy lifestyle choices that may reduce need for medication.

\section{CONCLUSION}

Accumulating research is in support of a dimensional approach in the understanding of the functional psychoses. Even though there is worldwide effort, no susceptible genes for schizophrenia or bipolar disorder have been identified. Regardless, strong evidence is available for genetic influences to exist and to be shared between schizophrenia and bipolar disorder. No conclusions can be drawn, due to the scarcity of the molecular research done on schizophrenia and bipolar disorders but it is hopeful over the next few years genes will be found that account for at least a proportion of these diseases. Only then the controversy over the nosology of psychotic disorders will finally be resolved.

Schizophrenia and Bipolar disorder are severe mental disorders affecting many human beings. Advances in research are very hopeful, but until a precise drug is found, addressing the social and psychological issues in patients and families are needed. Government policies and programmes need to enhancing facilities in the community for these persons and improve awareness about this condition which in turn will facilitate early treatment and social inclusion. 


\section{REFERENCES}

1. Kessler R C. Psychiatric epidemiology: selected recent advances and future directions. Bull World Health Organisation 2000;78:464-74.

2. Aschengrau A, Seage GR. ( ${ }^{\text {rd }}$ ed). Essentials of epidemiology in public health. Pub: Jones and Bartlett, Sudbury:Massachusetts; 2003.

3. Vieta E, Grunze H, Azorin JM, Faqiolini A. Phenomenology of manic episodes according to the presence or absence of depressive features as defined in DSM-5 : results from the IMPACT, self-reported online survey. J Affect Disord 2014;156:206-13.

4. Gottesman II. Schizophrenia genesis: the origins of madness. New York: WH Freeman; 1991

5. Goodwin FK, Jamison KR. Manic-depressive illness. New York: Oxford University Press; 1990.

6. Jablensky A. The 100-year epidemiology of schizophrenia. Am J Med Genetics 1999;67:103-5.

7. Smith A, Weissman M. Epidemiology. In Handbook of Affective Disorders. Edited by Paykel E. Edinburgh: Churchill-Livingstone; 1992.

8. Castle D, Wessely S, Murray R: Sex and schizophrenia: effects of diagnostic stringency, and associations with premorbid variables. Br J Psychiatry 1993;162:658-64.

9. Guze S, Robins E: Suicide and primary affective disorders. Br J Psychiatry 1970;117:437-8.

10. Van Os J, Jones $\mathrm{P}$, Sham $\mathrm{P}$, et al.: Psychosis as a continuum of variation in dimensions of psychopathology. In Search for the Causes of Schizophrenia, vol 4. Edited by Haffner H Gattaz W. Berlin, Heidelberg, and London: Springer.1999; Pp 59-80.

11. Van Os J, Jones PB. Neuroticism as a risk factor for schizophrenia. Psychol Med 2001;31(6):1129-34.

12. Sullivan PF, Kendler KS \& Neale MC .Schizophrenia as a complex trait: evidence from a meta-analysis of twin studies. Arch Gen Psychiatry 2003;60(12):1187-92.

13. Tsuang MT, Stone WS, Faraone SV . Genes, environment and schizophrenia. Br J Psychiatry 2001;40:1824.

14. McGuffin P. Nature and nurture interplay: schizophrenia. Psychiatr Praxis 2004;31:189-93.

15. Tienari P, Wynne LC, Läksy K, Moring J, Nieminen P, Sorri A, Lahti I, Wahlberg KE. Genetic boundaries of the schizophrenia spectrum: evidence from the Finnish Adoptive Family Study of Schizophrenia. Am J Psychiatry 2003;160(9):1587-94.

16. Clarke MC, Harley M, Cannon M. The role of obstetric events in schizophrenia. Schizophr Bull 2006;32(1):3-8.

17. Ludvigsson JF, Osby U, Ekbom A. Coeliac disease and risk of schizophrenia and other psychosis: a general population cohort study. Scand J Gastroenterol 2007;49:179-85.

18. Malaspina D, Brown A, Goetz D, Alia-Klein N, Harkavy-Friedman J, Harlap S, Fennig S. Schizophrenia risk and paternal age: a potential role for de novo mutations in schizophrenia vulnerability genes. CNS Spectrums 2002;7(1):26-9.

19. Xu B, Ionita-Laza I, Roos JL, Boone B, Woodrick S, Sun Y, Levy S, Gogos JA, Karayiorgou M. De novo gene mutations highlight patterns of genetic and neural complexity in schizophrenia. Nat Genet 2012;44(12):1365-70.

20. Buka SL, Tsuang MT, Torrey EF, Klebanoff MA, Bernstein D, Yolken RH. Maternal infections and subsequent psychosis among offspring. Arch Gen Psychiatry 2001;58(11):1032-7.

21. Arseneault L, Cannon M, Poulton R. Cannabis use in adoles- cence and risk for adult psychosis: longitudinal prospective study. BMJ. 2002;325(7374):1212-3.

22. Dean K, Murray RM. Environmental risk factors for psychosis. Dialog Clin Neurosci 2005;7(1):69-80.

23. Reiss F. Socioeconomic inequalities and mental health problems in children and adolescents: a systematic review. Soc Sci Med 2013;90:24-31.

24. Coyne CA, Långström N, Lichtenstein P, D'Onofrio BM. The association between teenage motherhood and poor offspring outcomes: a national cohort study across 30 years. Twin Res Hum Genet 2013;16(3):679-89.

25. Van Os J, Mc Guffin P. Can the social environment cause schizophrenia ? Br J Psychiatry 2003;182:291-2.

26. van Os J, Pedersen CB, Mortensen PB. Confirmation of synergy between urbanicity and familial liability in the causation of psychosis. Am J Psychiatry 2004;161(12):2312-4.

27. Selten JP, Cantor-Graae E, Slaets J, Kahn RS. Ødegaard's selection hypothesis revisited: schizophrenia in Surinamese immigrants to The Netherlands. Am J Psychiatry 2002;159(4):669-71.

28. Hanoeman M, Selten JP, Kahn RS. Incidence of schizophrenia in Surinam. Schizophr Res 2002;54(3):21921.

29. Cooper B. Schizophrenia, social class and immigrant status: the epidemiological evidence. Epidemiol Psichiatr Soc 2005;14(3):137-44.

30. Leão TS, Sundquist J, Frank G, Johansson LM, Johansson SE, Sundquist K. Incidence of schizophrenia or other psychoses in first-and second-generation immigrants: a national cohort study. J Nerv Ment Dis 2006;194(1):27-33.

31. Smith GN, Boydell J, Murray RM, The incidence of schizophrenia in European immigrants to Canada. Schizophr Res 2006;87(1-3):205-11.

32. Sullivan PF, Neale MC, Kendler KS. Genetic epidemiology of major depression: review and meta-analysis. Am J Psychiatry 2006;157(10):1552-62. 
33. Lichtenstein P, Yip BH, Björk C, Pawitan Y, Cannon TD, Sullivan PF, Hultman CM. Common genetic determinants of schizophrenia and bipolar disorder in Swedish families: a population-based study. Lancet 2009;373(9659):234-9..

34. Aukes MF, Laan W, Termorshuizen F, Buizer-Voskamp JE, Hennekam EA, Smeets HM, Ophoff RA, Boks MP, Kahn RS. Familial clustering of schizophrenia, bipolar disorder, and major depressive disorder. Genet Med 2012;14(3):338-44.

35. Merikangas KR, Cui L, Heaton L, Nakamura E, Roca C, Ding J, Qin H, Guo W, Yao-Shugart Y, Zarate C, Angst J. Independence of familial transmission of mania and depression: results of the NIMH family study of affective spectrum disorders. Mol Psychiatry 2014;19(2):214-20.

36. Vandeleur CL, Merikangas KR, Strippoli MF, Castelao E, Preisig M. Specificity of psychosis, mania and major depression in a contemporary family study. Mol Psychiatry 2014;19(2):209-13.

37. McGuffin P, Rijsdijk F, Andrew M, Sham P, Katz R, Cardno A. The heritability of bipolar affective disorder and the genetic relationship to unipolar depression. Arch Gen Psychiatry 2003;60(5):497-502.

38. Birmaher B, Axelson D, Monk K, Kalas C, Goldstein B, Hickey MB, Obreja M, Ehmann M, Iyengar S, Shamseddeen W, Kupfer D. Lifetime psychiatric disorders in school-aged offspring of parents with bipolar disorder: the Pittsburgh Bipolar Offspring study. Arch Gen Psychiatry 2009;66(3):287-96.

39. Nurnberger JI, Jr., McInnis M, Reich W. A high-risk study of bipolar disorder. Childhood clinical phenotypes as precursors of major mood disorders. Arch Gen Psychiatry 2011;68(10):1012-20.

40. Vandeleur C, Rothen S, Gholam- Rezaee M, Castelao E, Vidal S, Favre S, Ferrero F, Halfon O, Fumeaux $\mathrm{P}$, Merikangas KR, Aubry JM. Mental disorders in offspring of parents with bipolar and major depressive disorders. Bipolar Disord 2012;14(6):641-53.

41. Wozniak J, Faraone SV, Martelon M, McKillop HN, Biederman J. Further Evidence for Robust Familiality of Pediatric Bipolar-I Disorder: Results from a Very Large Controlled Family Study of Pediatric Bipolar-I Disorder and a Meta-Analysis. J Clin Psychiatry 2012;73(10):1328-34.

42. Merikangas KR, Yu K. Genetic epidemiology of bipolar disorder. Clin Neurosci Res 2002;2:127-41.

43. Kieseppä T, Partonen T, Kaprio J, Lönnqvist J. Accuracy of register-and record-based bipolar I disorder diagnoses in Finland; a study of twins. Acta Neuropsychiatr 2000;12(3):106-9.

44. Maier W, Lichtermann D, Minges J. Continuity and discontinuity of affective-disorders and schizophrenia: results of a controlled family study. Arch Gen Psychiatry 1993;50:871-83.

45. Kendler KS, McGuire M, Gruenberg AM. The Roscommon family study: affective-illness, anxiety disorders, and alcoholism in relatives. Arch Gen Psychiatry 1993;50:952-60.

46. Tsuang M, Winokur G, Crowe R. Morbid risks of schizophrenia and affective disorders among first-degree relatives of patients with schizophrenia, mania, depression and surgical conditions. Br J Psychiatry 1980; 137:497-504.

47. Kendler KS, Gruenberg AM. An independent analysis of the Copenhagen sample of the Danish Adoption Study of Schizophrenia, VI: the relationship between psychiatric disorders as defied by DSM-III in the relatives and adoptees. Arch Gen Psychiatry 1984;41:555-64.

48. Kendler K, Gruenberg AM, Tsuang M. Psychiatric illness in first-degree relatives of schizophrenic and surgical control patients: a family study using DSM-III criteria. Arch Gen Psychiatry 1985;42:770-9.

49. Kendler KS, Gardner CO. The risk for psychiatric disorders in relatives of schizophrenic and control probands: a comparison of three independent studies. Psychol Med 1997;27:411-9.

50. Angst J, Frey R, Lohmeyer B, Zerbin-Rudin E. Bipolar manic-depressive psychoses: results of a genetic investigation. Hum Genet 1980;55:237-54.

51. Baron M, Gruen R, Anis L, Kane J. Schizoaffetive illness, schizophrenia, and affective disorders: morbidity risk and genetic transmission. Acta Psychiatr Scand 1983;65:253-62.

52. Scharfetter C, Nusperli M. The group of schizophrenias, schizoaffective disorders and affective disorders. Schizophr Bull 1980;6:586-91.

53. Tsuang MT, Woolson RF, Fleming JA. Premature deaths in schizophrenia and affective disorders: an analysis of survival curves and variables affecting the shortened survival. Arch Gen Psychiatry 1980;37(9):979-83.

54. Frangos E, Athanassenas G, Tsitourides S. Prevalence of DSM-III schizophrenia among first-degree relatives of schizophrenic probands. Acta Psychiatr Scand 1985;72:382-6.

55. Baron M, Gruen R, Asnis L, Kane L. Schizoaffective illness, schizophrenia and affective disorders: morbid risk and genetic transmission. Acta Psychiatr Scand 1982;65:253-62.

56. Slater E, Shields J. Psychotic and Neurotic Illnesses in Twins: Medical Research Counsil Special Report 278. In London: Her Majesty's Stationery Office.1953.

57. Farmer A, McGuffin P, Gottesman I. Twin concordance for DSM-III schizophrenia: scrutinizing the validity of the definition. Arch Gen Psychiatry 1987;44:634-41.

58. Cardno AG, Marshall EJ, Coid B. Heritability estimates for psychotic disorders: the Maudsley Twin psychosis series. Arch Gen Psychiatry 1999;56:162-8.

59. Cardno AG, Rijsdijk FV, Sham PC, Murray RM, McGuffin P. A twin study of genetic relationships between psychotic symptoms. Am J Psychiatry 2002;159(4):539-45.

60. Gershon ES, Hamovit J, Guroff JJ. A family study of schizoaffective, bipolar I, bipolar II, unipolar, and normal control probands. Arch Gen Psychiatry 1982;39:1157-67.

61. Craddock N, Khodel V, Van Eerdewegh P, Reich T. Mathematical limits of multilocus models: the genetic transmission of bipolar disorder. Am J Hum Genet 1995;57:690-702. 
62. Bramon E, Sham PC. The common genetic liability between schizophrenia and bipolar disorder: a review. Curr Psychiatry Rep 2001;3:332-7.

63. Brown AS, Schaefer CA, Wyatt RJ, Begg MD, Goetz R, Bresnahan MA, Harkavy-Friedman J, Gorman JM, Malaspina D, Susser ES. Paternal age and risk of schizophrenia in adult offspring. Am J Psychiatry 2002;159(9):1528-33.

64. Kraepelin, E. Dementia praecox and paraphrenia. E and S Livingstone; 1919.

65. Sabb FW, Bearden CE, Glahn DC, Parker DS, Freimer N, Bilder RM. A collaborative knowledge base for cognitive phenomics. Mol Psychiatry 2008;13(4):350-60.

66. Greenwood TA, Braff DL, Light GA, Cadenhead KS, Calkins ME, Dobie DJ, Freedman R, Green MF, Gur RE, Gur RC, Mintz J. Initial heritability analyses of endophenotypic measures for schizophrenia: the consortium on the genetics of schizophrenia. Arch Gen Psychiatry 2007;64(11):1242-50.

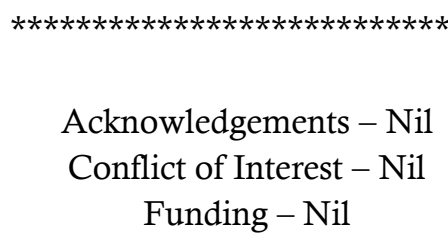

